\title{
Aprendizado da língua, uso e princípio de relação na Oficina-Escola de João Pessoa
}

Rocío Serrano Cañas ${ }^{*}$

\section{Resumo}

O estudo de caso que apresentamos neste trabalho aborda o tratamento do uso e do princípio de relação no aprendizado da língua, dentro do contexto formativo de uma oficina-escola, em contraste com a estrita tendência de adequação ao método, que parece imperar na atividade da sala de aula do modelo letrado. De um modo particular, os casos que são descritos e narrados neste trabaIho revelam uma série de situações nas quais existem forças antagônicas (de integração ou de exclusão), que incidem diretamente nas possibilidades educativas que apresentam o uso e o princípio de relação no aprendizado da língua. O estudo revela tendências à assimilação ao modelo padrão, por parte daqueles alunos mais interessados em serem legitimados moralmente e em atingirem um determinado status social. De outro modo, observa-se uma tendência ao uso da língua na qual os alunos fazem predominar a escuta significativa e a intensificação semântica para dar sentido ao que se quer dizer, dentro do âmbito da relação comunitária.

Palavras-chave: Aprendizado da língua. Integração. Trabalho. Comunidade.

\section{Introdução}

A situação linguística e pedagógica que se tratará neste estudo de caso envolve o espanhol como língua estrangeira (LE) para alunos lusofalantes, oriundos do nordeste do Brasil. Os alunos estavam inseridos em um contexto formativo caraterizado pela transmissão de um ofício e pelo aprendizado manual por meio da prática direta, o que podia favorecer uma prevalência do princípio de relação ${ }^{1}$ na sua aprendizagem. No contexto formativo da oficina-escola, o aprendizado manual está baseado na observação direta do fazer, junto a um mestre e junto aos aprendizes das respectivas oficinas, estabelecendo, desse modo, o princípio de relação

\author{
Recebido: 17/07/2014 - Aprovado: 29/11/2014 \\ http://dx.doi.org/10.5335/rep.v22i1.5192
}

Doutora pelo Programa de Linguística da Universidade Federal da Paraíba (UFPB). Professora efetiva do Curso de Letras/Espanhol da Universidade Estadual da Paraíba (UEPB). E-mail: rocioserrano03@gmail.com 
como eixo do processo formativo Dado esse contexto, o foco da análise serão as atitudes $^{2}$ que surgiram durante o aprendizado da língua estrangeira, o que, pelas observações realizadas, não poderia ser entendido sem a experiência de uso desses alunos na língua materna (LM) e sem o modo como foi realizado o processo de alfabetização e ensino da língua materna.

Por esse motivo, ao longo do estudo, refere-se ao aprendizado da língua, considerando uma continuidade que compreende o uso da língua materna e da língua estrangeira, pois, segundo observou-se, os aspectos atitudinais que surgiam no aprendizado da língua estrangeira não podiam ser compreendidos sem o substrato de uso na língua materna, um aspecto que pertence exclusivamente ao âmbito da comunidade. Também não poderia ser deixada de lado a escolarização prévia, na qual se fazia efetiva uma determinada prática de ensino da língua junto às diretrizes educativas determinadas pelo Estado (dois aspectos, a da prática do professor e a das diretrizes do MEC que, certamente, nem sempre eram concordantes na sala de aula).

Para realizar o estudo, partiu-se das observações que foram coletadas na pesquisa-ação do projeto $O$ trabalho da linguagem (por uma proposta de ensino/aprendizagem das LE e LM em contextos de formação profissionalizante), desenvolvido durante os anos de 2007 e 2008, na oficina-escola de Revitalização de Patrimônio Histórico de João Pessoa ${ }^{3}$. A atividade desse centro atinge a formação de jovens com perfil de risco social, por meio de ofícios referidos à revitalização do patrimônio arquitetônico e urbanístico. Desde a década de 1990 até recentemente, a Oficina-Escola de João Pessoa pertenceu ao programa de oficinas-escola na Ibero-América, impulsionado e financiado pela Agência Espanhola de Cooperação Internacional para o Desenvolvimento (Aecid). O programa foi iniciado na Espanha, durante os anos 1980, como uma alternativa formativa ao desemprego e ao fracasso escolar que colocava em perigo o futuro dos mais jovens e, na década de 1990, foi expandida na Ibero-América.

A filosofia formativa do programa de oficinas-escola possui um caráter patrimonial, pois está fundamentada no antigo princípio de aprender fazendo, que, desde antanho, caracterizou a formação no âmbito dos ofícios e que foi repassado de uma geração para a outra, por meio da complexa experiência do trabalho. De outro modo, o mencionado princípio pressupõe uma modalidade formativa baseada, principalmente, na incorporação da prática, no sentido de um conhecimento que se realiza no corpo.

No contexto formativo da oficina-escola, enfatiza-se a observação direta dos fatos, sendo que a fala encontra-se integrada plenamente no fazer, o que significa um alto grau de corporeidade no uso linguístico (o que neutraliza a especulação discursiva) e também uma necessidade de vínculo por intermédio do trabalho, uma vez que apenas é possível o aprendizado no relacionamento quotidiano com o mestre do ofício e na relação direta com os fatos que movimentam a prática. 
Existe, por conseguinte, um alto grau de experiência incorporada e de transmissão na fala, dentro da modalidade formativa das oficinas-escola, que situa o lugar do aprendizado na oficina e na obra, como sempre aconteceu nos antigos ofícios. Pode-se dizer que tais particularidades remetem ao fluxo de conhecimento comunitário, em que o centro é a própria atividade humana e a dinâmica das relações humanas que determinam o modo como se transmite, se preserva, se cristaliza ou se atualiza o que é conhecido.

Essa situação formativa é diferente da modalidade letrada de ensino em sala de aula, a qual, geralmente, vem estruturada por meio de um método e de um sistema de conteúdos, com uma grave tendência a centralizar a atividade formativa na figura do professor. Na sala de aula, frequentemente, a atividade não consegue transformar um trabalho concreto, fatual e útil, no qual o aprendiz deva intensificar ao máximo sua responsabilidade e suas capacidades, o que leva a delegar no que "o professor traz" para o ensino da matéria.

\section{0 uso integra, 0 método homogeneíza}

Essa breve caracterização da filosofia formativa das oficinas-escola proporciona as chaves para compreender melhor o contexto do estudo de casos que aqui se apresenta, sobretudo, no que diz respeito ao aprendizado da língua dentro de uma modalidade formativa que demostra estar determinada pela ênfase na fala incorporada no trabalho e na observação dos fatos, o que, de um modo geral, pode significar uma maior presença do uso comunitário e das capacidades naturais no aprendizado. A esse respeito, é necessário destacar que a atividade formativa das oficinas-escola está regida pelo princípio do aprender fazendo, dentro da longa tradição dos ofícios ${ }^{4}$.

Desse modo, a proposta formativa das oficinas-escola, principalmente nos seus inícios, veio denunciar o problema do fracasso escolar, diante da homogeneização dos modelos educativos, que significava também tentar igualar perfis linguísticos e cognitivos, dentro do modelo de ensino da sala de aula, que está vinculado estreitamente ao domínio sedentário da escrita e que parece se apresentar como válido de um modo excessivamente geral.

A problemática que envolveu o surgimento e o desenvolvimento das oficinas-escola revelava uma opacidade na diferença entre homogeneizar e integrar, na formulação das modalidades formativas nos tempos contemporâneos ${ }^{5}$, o que viria a ter um impacto direto na possibilidade de evoluir em um tratamento mais pragmático e flexível das questões linguísticas, ou seja, mais próximo da vida da comunidade, a qual pertence plenamente o uso da língua. 
$\mathrm{O}$ perigo de tentar homogeneizar por meio de um modelo educativo atinge também o tratamento das questões linguísticas, pois o que caracteriza o uso é sua realização dinâmica no âmbito comunitário, contrário à fixação pretendida com a aplicação geral de um método.

A tentativa de expandir a educação formal a todos os setores da sociedade, quando direcionada através de um modelo único, estabelecido pelo Estado e prestigiado socialmente, pode acabar sendo excludente das particularidades que caracterizam os distintos perfis humanos e, portanto, os distintos modos de aprendizado.

Embora, alguns jovens aprendam muito bem sob o efeito de um método, dentro da sala de aula, com um professor que ministra uma série de conteúdos, também é verdade que para outros, por distintos motivos (psicológicos e cognitivos, de origem familiar ou de entorno social), esta situação pressupõe um distanciamento do aprendizado.

Quando se trata das questões linguísticas, o problema se acentua, pois, o aprendizado e o estudo da língua encontram-se, necessariamente, atrelados à escrita e à leitura, dentro da lógica de conteúdos ministrados na sala de aula, mesmo tratando-se de uma língua estrangeira. A tendência dentro dos modelos educativos ocidentais (ou ocidentalizados) é tratar o aprendizado e o estudo de uma língua viva como se fosse uma língua morta, como o caso do latim.

No que diz respeito aos alunos da Oficina-Escola de João Pessoa, encontram-se inseridos em um entorno cultural altamente oral, no qual, a escrita e a leitura têm uma presença de baixa intensidade. No que se refere às elites, encontram-se fortemente instrumentalizadas, ainda muito atreladas à obtenção de títulos e de status sociais, derivados da antiga posse de terras.

A escolarização em língua materna, por sua vez, estava marcada por uma prática direcionada ao ensino de regras gramaticais, com uma tendência, por parte dos usuários, a estigmatizar o uso (de como "o povo fala mal" ou, no polo oposto, de como alguém que tenta se acomodar a norma culta soa "arrogante" e "enxerido"). Em alguns casos, o professor admitia as diretrizes do governo e tentava aplicar uma metodologia mais avançada intelectualmente, fundamentada em uma concepção da linguagem crítica e discursiva, porém, ainda fortemente centralizada no domínio da escrita no tratamento do uso da língua.

De outra forma, observa-se, também, um forte apego à língua materna, talvez reforçado pelo forte arraigo à terra e pelo predomínio da esfera familiar nos relacionamentos humanos, embora, também se percebesse que existia uma forte tendência ao abandono do lar por parte dos progenitores, permanecendo alguém que assumia a maternidade e a paternidade (em muitos casos os avós, alguma tia ou alguma outra mulher do bairro que recolhia a criança). 
Todos esses aspectos caracterizavam, com distinta intensidade, a experiência de uso dos alunos da oficina-escola e incidiam na situação de aprendizado da nova língua, estabelecendo distintas forças, por vezes opostas. Por um lado, aquelas que manifestam o valor integrador do uso, do que é particular dentro do aprendizado da língua, na linha da filosofia formativa das oficinas-escola e, por outro, aquelas que, de um modo excludente, determinam à adequação ao método que inibem, com distinta intensidade, o princípio de relação no aprendizado linguístico.

\section{As características metodológicas do estudo de casos}

A análise aqui apresentada foi realizada por meio da proposta qualitativa do estudo de $\operatorname{casos}^{6}$. Em fases anteriores da pesquisa-ação, tinha-se começado a atender ao caso particular, porém de um modo intuitivo e conversacional. Ao longo dos encontros com a equipe e, durante as conversas com as observadoras, foi surgindo, de uma maneira espontânea, a descrição e a narração de situações que remetiam aos fatos da própria pilotagem em sala de aula.

Nos primeiros relatórios, incorporou-se paulatinamente esses casos, como parte da análise dos resultados da pesquisa-ação, até começar incidir nesse material com mais precisão, partindo para a escrita de pequenos estudos que, nas suas particularidades, revelavam dilemas referidos ao uso e ao princípio de relação no aprendizado da língua, tais como a repercussão estimuladora ou inibitória do ideal formal, o valor educativo do silêncio, a relação com a figura de autoridade, a corporeidade na fala ou as possibilidades de ser manifestada a individualidade no uso linguístico. $\mathrm{O}$ estudo de casos fornecia um substrato conversacional e narrativo para o desenvolvimento conceitual e teórico da pesquisa sobre o aprendizado da língua pelo uso ${ }^{7}$.

Agora, de um modo mais consciente, o interesse por esta modalidade de análise se justifica por dois motivos que atingem o modo de proceder do pesquisador e do professor. Em primeiro lugar, pela possibilidade de tratar os elementos desviantes dentro da prática educativa, aqueles que não se ajustam ao que o pesquisador ou o professor podem prever e controlar na atividade educativa, mas que, por algum motivo, provocam algum efeito na sua sensibilidade e atraem sua atenção como profissional. Em segundo lugar, o estudo de caso interessa pelas possibilidades que oferece para o desenvolvimento da língua ordinária ${ }^{8}$ no tratamento de problemas educativos referidos ao uso.

Nessa linha, o estudo de casos favorece a narração, descrição e interpretação de situações concretas, vivenciadas, que apenas podem ser abordadas desde o uso comum, aquele que está inserido na vivência do trabalho quotidiano do professor, no convívio e na conversa com outros colegas. 
Esse último aspecto, o da conversa dentro do convívio profissional, no âmbito educativo, apresenta-se como fundamental no que se chama desenvolvimento da língua ordinária, pois, ao passo que se narra e se descreve, por vezes, se avança alguma interpretação do que acontece no aprendizado. É possível detectar problemas na expressão linguística (de tipo sintático ou semântico) e áreas do sentido ainda sem definir explicitamente, o que significa explorar o potencial dos termos que usamos comumente, estabelecendo novas associações e estimulando variações semânticas, sem perder o vínculo com a língua de convívio, o uso quotidiano.

Os problemas linguísticos no estudo de caso remetem, portanto, à compreensão dos fatos vivenciados e aos processos de pensamento por parte do professor e também do pesquisador ${ }^{9}$.

No que se refere aos procedimentos da pesquisa, tomou-se como unidade deste estudo de casos os dois grupos observados durante a pesquisa-ação na Oficina-Escola de João Pessoa. Seguindo as recomendações da coordenadora pedagógica, e com a diretora do centro, a minha atividade dentro da oficina-escola se realizou por meio de uma Oficina de Espanhol, que funcionou dois dias por semana, em dois espaços distintos, um primeiro em sala de aula (no início do dia) e outro no convívio (ao longo do dia). O convívio com os alunos acontecia durante o trabalho nas distintas oficinas (alvenaria, marcenaria, serralharia, jardinagem e bens móveis) e também na obra de restauro. Foram criados dois grupos de pilotagem com alunos das distintas oficinas: um primeiro grupo formado com alunos de alvenaria e bens móveis e um segundo com alunos de jardinagem, serralharia e marcenaria.

O material utilizado para o estudo pode ser caracterizado segundo a proximidade aos fatos: i) mais direto: as anotações que coletei ao longo da pesquisa-ação (com registros das conversas e das situações dentro e fora da sala de aula) e os textos elaborados pelos alunos; ii) mais indireto: os relatórios que fui elaborando (nos quais, além da descrição da atividade junto aos alunos, já se fazia presente minha interpretação e análise), assim como os artigos nos quais se recolhem e analisam os resultados de estádios anteriores da pesquisa-ação.

No estudo, abordo as situações que mais impressionaram na minha atividade como professora e pesquisadora, por serem indicadores da problemática que envolve o uso e o princípio de relação no aprendizado da língua. Talvez possa dizer que o impacto se traduz em uma insistência na minha memória de tais momentos vivenciados durante o trabalho com os alunos da oficina-escola e no convívio com a equipe. Nesse sentido, continuo explorando o que é desviante dentro do aprendizado da língua, agora no contexto específico da Oficina-Escola de João Pessoa, caracterizado, como já foi indicado, por uma proposta formativa que enfatiza a transmissão do ofício através da fala comunitária e da observação direta dos fatos. 


\section{0 aprendizado da língua na Oficina-Escola de João Pessoa}

\section{A sala de aula e o convívio na Oficina de Espanhol}

Durante a pesquisa-ação, na Oficina-Escola de João Pessoa, decidi observar dois espaços distintos, pois, dado o funcionamento do centro, existia a possibilidade de acompanhar os alunos durante seu trabalho nas oficinas e na obra. Essa situação era uma novidade para mim, pois, até esse momento, minha prática como professora de LE sempre tinha acontecido em sala de aula. De outro modo, o fato de ter esses dois espaços me permitia estabelecer um contraste, entre um contexto controlado pelo método e uma situação de aprendizado inserida no trabalho.

Para a sala de aula estabeleci uma ação baseada na conversa, na qual eu falava em espanhol e os alunos em português (com tentativas espontâneas na língua estrangeira). Essa ação parecia a mais coerente com o princípio de aprender fazendo que regia a proposta formativa da oficina-escola, pois, se o ofício se aprendia pela prática direta e pela transmissão de um mestre para o aprendiz, seria coerente que no lugar do aprendizado de uma nova língua se tivesse a fala inserida no convívio do trabalho.

É nesse sentido que se entende a conversa, pensando no seu potencial educativo, em contraste com outros modos de fala, como a discussão ou o diálogo, em que predomina o controle discursivo sob o relacionamento humano ${ }^{10}$.

Além disso, é possível ter em conta o papel que pode cumprir a conversa no aprendizado da língua, por incluir necessariamente uma relação direta com o uso linguístico, dentro de uma situação autêntica, onde as distintas partes estão na mesma altura, de um modo contemporâneo. Nesse sentido, considera-se primordial a noção de trabalho, que remete à função e à responsabilidade dentro de uma ação que envolve o convívio, permitindo nivelar os interlocutores, com um maior grau de simultaneidade e contemporaneidade, pois pertencem a um mesmo momento e a uma mesma ação.

Os momentos de convívio ajudaram a dissolver, paulatinamente, a rigidez e a rapidez da postura de professora, proporcionando um novo âmbito de trabalho, mais voltado para a observação das atitudes e crenças que surgiam no aprendizado da língua. Embora, inicialmente, eu, como professora, tivesse expectativas de resultados formais de aprendizado da língua estrangeira, aos poucos, como explicarei adiante, fui mudando o teor da atividade, de professora para professora/observadora. Isso influiu também na mudança do foco da atividade, de uma procura imediata dos resultados formais, para uma maior atenção e uma melhor compreensão das atitudes em relação ao uso da língua. 
Nesse contraste entre a sala de aula e o convívio, uma das primeiras observações que registrei já estabelecia uma distinção entre o primeiro e o segundo grupo. Um aspecto que se revelou (e que foi corroborado pela diretora e pela coordenadora pedagógica) foi a influência que os instrutores das respetivas oficinas exerciam sobre os alunos. A maneira como os alunos agiam durante os momentos em sala de aula e de convívio estava fortemente condicionada pela relação que tinham estabelecido com a figura da autoridade, mais ou menos distorcida.

No primeiro grupo, existia um vínculo fortemente baseado na insuficiência moral, enquanto que, no segundo grupo, o relacionamento com os instrutores estava mais baseado na capacidade e na possibilidade de aprender pelo trabalho. $\mathrm{O}$ relacionamento com a figura de autoridade mostrou-se como um fator condicionante, dada a quebra violenta que muitos alunos apresentavam no relacionamento com o pai e com a mãe, o que, em alguns casos, os predispunha a ser facilmente "apadrinhados" ou "amadrinhados".

No primeiro grupo, em que os instrutores funcionavam como a figura de um juiz moral (assumindo, por vezes, a voz exagerada de um pai ou de uma mãe), os alunos mostravam um maior apego ao modelo padrão de sala de aula (exigindo aprender palavras em espanhol e apontando para a atividade do professor ao redor do quadro). A partir da maneira como os alunos lidavam com o instrutor, na conversa, foi percebida uma forte carga de julgamentos sobre a conduta dos colegas, ou sobre o grupo em geral, na maioria das vezes, expressada de um modo impessoal, como uma generalização, formalizada na terceira pessoa do singular, um "a gente" ou um "os alunos", "a turma". Já, durante os momentos de convívio, percebi que a relação comigo mudava, deixava de ser "professora de espanhol" e passava a ser "a Rocío" que conversava com eles sobre seu trabalho, as coisas da sua vida (família, planos de futuro, amigos, etc.), em um movimento de ida e volta entre a língua estrangeira e a língua materna.

Existia, portanto, uma forte descontinuidade entre a sua atitude em sala de aula e em momentos de convívio. No primeiro espaço, prevalecia um comportamento aderido ao modelo padrão (excessivamente centralizado no professor), com uma intensificação do julgamento moral (entendendo a figura de autoridade como um juiz da conduta). Na sala de aula, os alunos projetavam em mim esse ideal de professor, que "ensinava bem" e que estabelecia o que era "correto e incorreto" moralmente. O grupo apresentava um baixo nível de relação na aula, sendo raras as situações de conversa entre eles, exigindo constantemente que eu reproduzisse $o$ método de ensino baseado na cópia de frases e palavras, com sua devida tradução.

Claramente, o contexto de sala de aula vinha reforçar, nesse grupo, uma concepção de língua morta, despojada do uso comunitário e atrelada a um asfixiante 
relacionamento moral com a figura de autoridade, que incentivava o isolamento e a competitividade entre os alunos ${ }^{11}$.

Durante o convívio no trabalho, a atitude de alguns deles (aqueles menos defensivos e os que estavam menos preocupados em demostrar resultados) era mais flexível, conversavam entre eles durante o trabalho na obra e focalizavam aspectos positivos do que estavam realizando na sua prática. Nesses momentos e com esses alunos, foi se estabelecendo uma relação de escuta, a partir da qual se cobrava sentido no uso da nova língua.

Apesar da rigidez predominante, dentro desse primeiro grupo, houve momentos nos quais os alunos conseguiam estabelecer uma continuidade entre a sala de aula e os momentos de convívio, conseguindo, desse modo, liberar o princípio de relação e voltando-se para o uso dentro do aprendizado da nova língua.

Isso se manifestou no caso de uma aluna que, na sua primeira autoavaliação, destacou o aprendizado durante os momentos de convívio: "mas também durante as conversas na obra, aqui na Tito Silva, no caminho quando vamos para a obra". Foi uma aluna com a qual tinha existido uma boa proximidade, pois se mostrava acessível à minha presença e eu sentia que ela desfrutava dos momentos nos quais mostrava e explicava o trabalho de restauro que estava realizando na obra.

A sua percepção da Oficina de Espanhol parecia ir além do modelo padrão do ensino da língua, centralizada no professor e na aplicação de um método, passando a focalizar a relação que flui por meio da conversa, como lugar primordial do aprendizado linguístico: "eu presto atenção quando vamos para a obra, eu presto bem atenção quando Rocío está conversando comigo e quando não entendo eu peço para ela repetir novamente e a minha dificuldade vai diminuindo cada vez mais". Mais à frente, a única palavra que aparecia escrita na língua estrangeira dentro da sua autoavaliação era aquela que recolhia seu ponto de interesse, "español”, tanto para se referir à língua quanto à pessoa que fala essa língua: "nunca pensei que um dia poderia conversar com um español".

Outro aluno do mesmo grupo mostrou uma atitude ambígua na sua autoavaliação. Por um lado, ele exigia que nas aulas houvesse mais escrita para "conhecer palavras" em espanhol, mas, ao mesmo tempo, achava melhor aprender na obra, como se observa em sua explicação: "porque falamos de vários assuntos e de coisas que tem mais a ver comigo e assim eu me interesso mais".

A sua atitude na sala de aula era distinta da atitude na obra, sendo que, no primeiro contexto, o aprendizado da nova língua se transformava em "uma brincadeira" para o aluno e em um "jogo sério" para o professor. No contexto da sala de aula não consegui participar do mesmo modo que durante o convívio na oficina e na obra, momentos nos quais prevalecia a conversa espontânea. 
Diferentemente do primeiro, no segundo grupo observei que os momentos de sala de aula eram muito mais incômodos para os alunos, isto é, eles reagiam corporalmente ao fato de terem que estar sentados na cadeira durante o tempo dedicado à aula. Daí foi menos frequente a exigência de uma "aula de espanhol", seguindo o modelo padrão de copiar e traduzir palavras, como exercícios de gramática, direcionados pelo professor. Nesse segundo grupo, era mais ausente o julgamento moral e, portanto, os relacionamentos dentro do grupo eram muito mais ativos, possibilitando uma conversa natural da sala de aula e também depois, nos momentos de convívio.

Existia, então, uma continuidade entre a sala de aula e o convívio, forjada no fio da conversa, a qual foi possibilitando uma relação mais constante de escuta entre nós, facilitando, como será visto mais adiante, o tratamento de certos nós entre mim e alguns alunos, em particular. Podemos dizer que, nesse segundo grupo era muito mais ativo o princípio de relação, no sentido de privilegiar mais o sentimento de pertença por meio do uso linguístico, do que a rápida adequação a um método ou a prática dos julgamentos morais. Nesse grupo, se intensificava o uso da língua, integrando nele os distintos movimentos da conversa, a personalidade de cada aluno e as situações, por vezes bizarras, chatas e conflitivas, que surgiam ao longo do convívio.

Por sua vez, nesse grupo era mais frequente a recepção dinâmica da língua estrangeira. Podemos dizer que, em comparação com o primeiro grupo, a situação de uso da nova língua era menos mecânica, já que repetiam sons que chamavam sua atenção ou que provocavam risos por serem esquisitos ou palavras que identificavam como importantes na conversa.

Por exemplo, quando falamos das suas famílias, uma das alunas intensificou a palavra "padre" porque ela, segundo seu ânimo, o considerava como morto, "mi padre está muerto", foi o primeiro enunciado que ela disse em espanhol. Já para outro aluno, a palavra "padre", remetia à prática do ofício, pois trabalhava com o pai como marceneiro desde que era criança.

Os alunos desse grupo paravam quando não entendiam e me obrigavam a repetir o que estava dizendo e manifestavam-se de um modo mais sensível sobre o uso da língua estrangeira. Como foi o caso da aluna mencionada anteriormente, a quem, em uns dos momentos de convívio, sugeri falar comigo um pouco em espanhol. Ela mostrou estranhamento diante dessa situação de uso, como se lhe parecesse alheia ou, talvez, precipitada, ela disse: "é estranho falar em espanhol, é forçado". Porém, nunca manifestou nenhum estranhamento diante do fato de eu falar com ela constantemente em espanhol. De algum modo, essa aluna se manifestava em relação à situação de uso, discernindo e valorando sobre o que estava acontecendo (talvez com certa resistência a se adentrar em uma língua distinta, 
quando não encontrava necessidade para justificar esse movimento). Assim, eu usava o espanhol, porque era minha língua materna e ela usava a sua. Restava entre nós um "escutar ao outro", no movimento das duas línguas, ativado pelo princípio de relação.

\section{A sensação de insuficiência no aprendizado da língua}

Durante os momentos em sala de aula, um dos sintomas que identificamos, sobretudo no primeiro grupo, foi uma forte dependência da escrita com a figura do professor e com o método de ensino, em um movimento que afastava os alunos da sua própria experiência de uso. Percebi que a escrita tinha que vir através do professor, isto é, ser um exercício imposto, a maioria das vezes, por meio da cópia de frases ou textos no quadro, uma prática muito corrente na aula, tanto no ensino de língua materna quanto no de língua estrangeira.

Frequentemente, os alunos pediam que eu escrevesse no quadro para eles copiarem, já que, desse modo, "aprenderiam melhor" o espanhol. Também queriam que fizesse ditados e exigiam que eu fornecesse um tema para escrever, pois achavam "insuficiente" escrever a partir do que falávamos na sala e durante o tempo de convívio ("sempre estamos escrevendo sobre nós", diziam frequentemente).

Por trás das suas exigências, revelava-se uma frágil consciência linguística, pois acreditavam ser "insuficiente" a própria experiência como usuários da língua, ou seja, que a comunidade de uso (e com ela a memória que é compartilhada no fluxo do uso linguístico) era insuficiente para poder entrar no espaço da escrita. Essa insuficiência remitia, também, a um apagamento da própria natureza, como principal impulsora da linguagem no homem, tanto na sua dimensão orgânica quanto cultural. O uso, no caso destes alunos, era o lugar do estigma linguístico ("falar correto ou incorreto") e da manipulação, pois era negada sua qualidade de referente comunitário.

O problema não era tanto a presença de um método e de um professor no seu ideal de aprendizado, mas que estes se apresentassem como um implante ${ }^{12}$, que vem substituir uma raiz que se acredita não ser suficientemente adequada (em termos estéticos, morais ou epistemológicos) para os processos formativos e educativos das novas gerações.

Apesar de estar em uma situação de aparente fracasso diante do modelo padrão, mesmo dentro de um contexto formativo baseado nas habilidades naturais e na transmissão do ofício por intermédio da fala, observou-se que, nos alunos da oficina-escola, surgiam atitudes e crenças muito semelhantes, as que já tinham sido identificadas em contextos de educação regulada pelo Estado (colégios e uni- 
versidade), sobretudo, no que diz respeito ao apagamento da natureza e da comunidade no aprendizado, em favor do método e do professor que parecem ser antídotos (que melhoram, aperfeiçoam, completam, sistematizam, etc.), diante dessa crença internalizada de insuficiência.

O perfil do aluno da Oficina-Escola de João Pessoa em relação à escrita era um perfil de semiletrado, pois todos eles tinham passado pela alfabetização e pelo ensino escolar da ortografia e da gramática da sua língua materna, atuando, este último como reforço prescritivo do erro linguístico. Em alguns casos, também tinham recebido aula de uma língua estrangeira (inglês), por meio de um modelo muito parecido ao da língua materna, ou seja, dentro de uma concepção de língua morta ${ }^{13}$.

Não eram, portanto, alunos alheios ao universo da escrita. Pelo que observei durante a minha pesquisa-ação, a sua prática de escrita estava condicionada à sala de aula, seguindo o modelo educativo estabelecido pelo Estado, que centraliza toda a atividade no professor e no método de ensino, convertendo a língua em um conteúdo puramente formal, uma lista, descontextualizada de regras e de convenções, despojada da sua dimensão orgânica e do referente vital de uso.

Podemos dizer que, segundo as situações que apresentavam os alunos, a escrita estava tomada pelo modelo letrado estabelecido pelo Estado, o que trazia sérias implicações educativas, principalmente no que se refere à legitimidade do uso comunitário e à continuidade entre fala e escrita no processo de aprendizado e de estudo da língua materna ou estrangeira. Essa problemática se intensifica, ainda mais, no caso do português do Brasil, pela sua situação de diglossia, derivada da forte estratificação social, que acarreta a negação do referente comunitário (como se fala, o que a comunidade diz) em prol de um modelo normativo (o que a gramática, seguindo o modelo do português de Portugal, estabelece), em consequência, distante da realidade do uso ${ }^{14}$.

Sobre a relação norma/uso dentro do aprendizado da língua materna, a coordenadora pedagógica da oficina-escola alertou sobre a falta de domínio da convenção ortográfica e me mostrou os relatórios que escreviam mensalmente sobre a prática da obra e o trabalho nas oficinas. Ela me indicou que, em muitos casos, estavam cheios de erros ortográficos.

Percebi que o que ela chamava de erro correspondia a um fenômeno muito comum na prática daqueles que não possuem um pleno domínio da escrita, pois os alunos transcreviam a pronúncia na escrita, simplificando ou confundindo o uso das letras, por exemplo, "umiude" e "deichar", com "humilde" e "deixar", "esfosá" e "ganhá" com "esforçar" e "ganhar", "oficil” com "oficio", "profição" e "profisão" com "profissão". Essas alterações ortográficas mostravam que, no caso desses alunos, seu principal referente continuava sendo a fala, com efeito, dentro da sua variante. 
Junto aos problemas de ortografia, a coordenadora vinha observando erros de gramática, não apenas na escrita, mas também na fala, no sentido de formas de variação, estigmatizadas como vulgares, nas quais se perdia a concordância nominal ("os menino", por vezes também "os meninu", em vez de "os meninos") ou verbal ("nós vai" em vez de "nós vamos"), ou se reformulava a posição e função dos pronomes pessoais ("pediu para mim fazer" em vez de "para eu fazer"), entre outros. $\mathrm{Na}$ língua estrangeira, os alunos seguiam um procedimento parecido, de "transcrição" do que ouviam, seguindo aquela tendência de tomar a fala como referente da escrita, sem conseguir dominar plenamente as convenções que guiam o processo de escrita.

$\mathrm{Na}$ verdade, melhor do que "erros", um julgamento muito comum na hora dos falantes brasileiros avaliarem o uso da sua própria língua, podia-se falar em fatos do uso da língua e em desajustes no domínio da convenção, que podiam ser explicados pela observação do uso linguístico, em vez da avaliação prescritiva de "correto ou incorreto". Os primeiros são frutos da variação própria de uma língua viva, dando lugar a formas mais vulgares que convivem com outras cultas no contínuo do uso linguístico. $\mathrm{E}$ os segundos podiam ser explicados pela tendência a identificar a letra com um som, quando ainda se tem a fala como único e principal referente, $o$ que pode indicar também um forte apego à comunidade de partida, da qual não se consegue ou não se almeja sair.

Seja como for, esses aspectos da escrita nos informavam de uma forte adesão aos referentes da fala, lembrando aqueles de quem, inicialmente, tinham escutado o fluxo da língua. A questão era, portanto, que na sua prática de escrita, a fala era ainda o principal referente, pois eram muito excepcionais os momentos de uso da escrita e de leitura, além da sala de aula, já que o entorno humano dos alunos ainda era predominantemente oral.

Nesse sentido, foi chamativa a descrição que uma aluna fez de seu bairro em uma das sessões em sala de aula. Os três elementos que destacou foram: "homens bebendo nos botecos das esquinas, um cemitério e uma quadra de futebol". Durante a pesquisa-ação, surgiram perguntas a este respeito, que compartilhei com a coordenadora pedagógica. Perguntava-me como chegar à escrita e à leitura, sem ser unicamente pelo implante de um modelo de sala de aula, quando a comunidade de partida não acompanhava essa necessidade: qual era, portanto, a função que o professor devia cumprir nessa situação, na qual a vida da comunidade estava tão afastada da escrita? Também me inquietava como os alunos podiam partir para a escrita/leitura de uma palavra, não apenas ouvindo ela, mas sobretudo escutando-a, através de um relacionamento de confiança, em que as coisas aconteciam dentro do convívio.

$O$ resultado que se observava era uma quebra na relação entre fala e escrita dentro do aprendizado destes alunos. A fala era apagada sob o estigma do erro e a 
escrita tinha sido instalada como um "implante" do modelo letrado, quando ainda as comunidades não tinham desenvolvido práticas de leitura e de escrita próprias, vinculadas ao seu convívio comunitário, que pudessem constituir com um uso próprio.

No caso do aprendizado da língua estrangeira, como visto, ativavam-se as mesmas crenças, principalmente, nos momentos de sala de aula, em que aprender uma língua estrangeira, para a maioria, passava também por um modelo implantado, no qual o professor, desde seu domínio do conteúdo e do método, escrevia palavras, frases e textos no quadro e os alunos copiavam.

Foi o caso de um aluno que, em uma das autoavaliações, afirmou que "a professora ensinava com esforço, determinação e vontade", restituindo, dessa forma, a imagem ideal que tinham do professor. Em outro momento, um dos alunos revoltou-se na sala de aula e me chamou de "preguiçosa" porque, segundo ele, eu "não ministrava aula", apenas conversava com eles em espanhol. Segundo sua reação, deveria escrever no quadro, pois esse era o trabalho do professor. Este era um aluno que, segundo a coordenadora, tinha se deixado levar muito rápido pela imagem de "bom aluno" e tinha mostrado ostentação, já que, com o salário que recebia da oficina-escola, começou a ter certo poder aquisitivo. A tentativa de confronto justificava-se como um modo de se reafirmar perante a figura de autoridade, tentando provocar e desequilibrar por meio do modelo, um jogo que pretendia neutralizar o princípio de relação. Sua exaltação do método o situava acima dos outros colegas, sobretudo aqueles que se sentiam "menos fortes", "menos bons" que ele, mas, nos quais, coincidentemente, era muito mais ativo o senso de pertença. Voltarei sobre esse caso, pois vai servir como ponto de partida no seguinte parágrafo.

Em uma tendência distinta, apresentaram-se alguns casos que se desviaram e forneciam um material importante para continuar compreendendo esse princípio de relação dentro do aprendizado da língua, no contexto específico da oficina-escola.

Em alguns alunos, observei certa indiferença em relação à escrita que parecia estar associada a um desconforto ou um "sentir-se fora do lugar" dentro da sala de aula. Ao longo do convívio, percebi que esses eram os que estavam menos condicionados pela presença do professor e pela adequação ao método de sala de aula. Nesses casos, existia uma plena adesão ao aprendizado do seu ofício (marceneiro, pedreiro, restaurador) e seguiam, de um modo coerente, o seu estilo de aprendizado, caracterizado pelo predomínio da fala e o desenvolvimento das suas habilidades, dentro do âmbito específico do trabalho.

Concretamente, foi importante o caso de um aluno da oficina de alvenaria que, durante os momentos de sala de aula, tinha se mostrado indiferente (às vezes se jogava na cadeira), porém, durante o convívio me deixava estar próximo dele, observando como colocava o piso da obra de restauro. Chamou a atenção que, no 
desempenho do seu trabalho de alvenaria, a sua atitude (e sua postura corporal) era completamente ativa e íntegra, como um aprendiz que já tinha incorporado completamente seu ofício. Um dia falei para ele, em espanhol, que eu tinha observado que preferia trabalhar sozinho. Ele me respondeu surpreso: "você percebeu?".

Nesse momento, tinha se ativado o princípio de relação no uso da língua, pois existia uma compreensão mútua, embora em duas línguas distintas, que tinha se realizado através da presença e da escuta do outro, neste caso, com uma predominância dos momentos de silêncio por ambas as partes.

Esse aluno, durante a conversa na obra, tinha falado que queria ser um bom pedreiro, pois esse era o ofício que tinha escolhido. Por meio deste caso, entendi, também, a importância que poderia ter o fato de ser percebido por outra pessoa, através de um movimento de incorporação do outro a nosso mundo, que se realizava pelo uso da língua, e que também ajudava na tomada de consciência da nossa existência e na definição da maneira como cada um está no mundo.

Houve outros dois alunos que apresentaram um caso semelhante. Diferente dos momentos em sala de aula, durante o convívio na oficina de marcenaria e bens móveis e na obra, conseguia estabelecer uma conversa com eles, na ida e na volta do espanhol para o português, o que nos permitia avançar para uma situação de autenticidade, na qual ambos os lados, o eu e o tu ${ }^{15}$, encontravam-se na mesma posição e mostravam um interesse por se conhecer. Também nesses últimos dois casos, era muito nítida a adesão ao aprendizado do seu ofício, no caso do aluno de marcenaria, ademais, por ser o ofício que tinha aprendido com o pai.

O interessante desses casos é a maneira como o uso, levado no ritmo da conversa, permitiu integrar atitudes que divergiam do que se esperava do aprendizado da nova língua. Se, como professora, tivesse me guiado unicamente pelo método de ensino (quadro, livro, exercícios, etc.), me restringindo à sala de aula, esses alunos teriam se afastado do aprendizado da nova língua, o qual, na sua situação, significou silêncio e escuta do que o outro queria dizer ${ }^{16}$. O movimento vinha a reafirmar, por outro lado, a modalidade de aprendizado baseada na prática tradicional do ofício, em que não existe divisão entre o conhecimento, a ação e o uso da língua.

\section{A escrita como parte da conversa}

Um dos momentos críticos da pesquisa-ação, na oficina-escola, aconteceu quando um dos alunos do segundo grupo tentou me confrontar, já que, segundo ele, eu não estava dando aula, não escrevia no quadro (frases, palavras, traduções), como deveria fazer um professor. 
A crise manifestava uma necessidade de se reafirmar perante a figura da autoridade, pois isso lhe reforçava pessoalmente na frente do grupo, o que era muito sintomático. Como já se indicou, a implantação de um método mobiliza atitudes competitivas e defensivas, distintas dos processos de aprendizado nos quais permanece ativa a relação de pertença através da escuta. Nessas últimas prevalecem valores comunitários, que favorecem o sentido do limite ${ }^{17} \mathrm{e}$ a compreensão do outro.

No caso desse aluno, ele já tinha manifestado, dentro da oficina-escola, outras tentativas de se sobressair, pois tinha dado mostras de poder ser um bom aluno e tinha começado a ter um pequeno nível aquisitivo. A minha resposta a ele foi o silêncio. Perguntei ao resto dos colegas o que achavam. Percebi que a reação do colega tinha vindo estimular a necessidade de adequação ao método de outros colegas, pois alguns aproveitaram para manifestar a necessidade de uma "aula com palavras e frases para copiar no quadro".

É importante dizer que esse grupo era o que tinha se mostrado mais sensível diante de uma proposta de aprendizado da língua estrangeira pela fala. Era o grupo menos competitivo, e com os membros que mais se relacionavam entre si. Porém, a fragilidade na consciência do potencial dessas qualidades e dessa sensibilidade (talvez, por uma falta minha de ter nomeado e valorizado mais claramente suas atitudes), foi motivo suficiente para que, nesse dia, o colega arrastasse o resto da turma para uma rua sem saída.

A única que reagiu diante da inércia do grupo foi uma aluna que falou em voz alta e depois escreveu em um papel que ela queria continuar da mesma forma, conversando na aula e durante o trabalho. Era a mesma aluna que tinha falado, em espanhol, que seu pai tinha falecido e, às vezes, era rude e agressiva, mostrava insegurança e uma baixa autoestima. Nesse dia ela escreveu: "Nos ablamos sobre cosas que queríamos em las clases e yo acho melho continuarmos com o mesmo esquema do ano passado. Um momento nos hablamos e o resto de la classe nos escrebiamos un poco de tudo que hablamos".

Pelo que se pode observar, essa aluna escreveu em espanhol as palavras que eram determinantes para expressar sua intenção, como se esse fosse um recurso para enfatizar os elementos mais significativos da sua expressão, nesse caso, a primeira pessoa (yo) respondendo ao colega que tinha exigido escrever copiando do quadro e a modalidade de trabalho dentro da Oficina de Espanhol (hablamos, em relação a escrevíamos un poco), pois estava fundamentada na fala, da mesma maneira que o aprendizado do ofício.

O momento de crise conduziu a mudanças dentro desse grupo. Com a coordenadora pedagógica, decidi que o melhor era eliminar os momentos de sala de aula e realizar a Oficina plenamente durante o convívio com os alunos. Coincidentemente, 
ao liberar o grupo da sala de aula, o aluno que tinha criado o confronto não voltou a se aproximar, enquanto que os outros colegas me incluíram na sua atividade no ofício (adentro com pequenas atividades de jardinagem e marcenaria), em que era possível a conversa no aprendizado da nova língua.

Nesse espaço conversacional, o que direciona o aprendizado é o que se quer dizer, como exercício da intenção, que se faz possível quando existe alguém que está escutando, dentro da dinâmica da relação humana.

É importante esclarecer que a intencionalidade ${ }^{18}$ não é entendida aqui de um modo discursivo, mas sob o fluxo da relação humana, que movimenta o sentido quando a palavra está ancorada no convívio. De fato, como expliquei, foram várias as ocasiões nas quais quando perguntei para os alunos o que queriam dizer, a resposta era o silêncio. Mas, não era tanto um silêncio de não saber. Parecia mais um silêncio de não achar necessária a pergunta, pois o que tinham falado já dizia o que queriam dizer, se eu não compreendia era porque, talvez, não compartilhava o mesmo mundo de referências. Ou talvez, seu silêncio era fruto de certa estagnação no uso linguístico, devido a um soterramento dos relacionamentos humanos, já que avançar no sentido, na intencionalidade, também é avançar no relacionamento com si próprio e no movimento da conversa com o outro.

Por meio desse silêncio, compreendi que a pergunta podia supor para eles um gesto excessivamente discursivo e intelectual da minha parte, que, em outras fases da pesquisa-ação, mais focadas na atividade em sala de aula, tinha me servido como "instrumento" para explorar essa dimensão do sentido, mas que, neste novo contexto, parecia não funcionar. No entanto, também observei que, dentro do universo de relacionamentos dos alunos, não era frequente a conversa, entre um eu e um tu, que conseguem estar à mesma altura, com uma posição de escuta suficientemente ativa como para intensificar a intencionalidade.

Além disso, o mais frequente na realidade desses alunos eram formas violentas de silêncio, de culpa e de coação, provocadas pela desestruturação familiar, pelo abandono do espaço comunitário; formas de silêncio derivadas de uma expressão doutrinária diante dos fatos interiores e dos acontecimentos do mundo. Se a minha pergunta o que você quer dizer era, talvez, excessivamente intelectual e discursiva para os alunos da oficina-escola, o que vinha do seu lado podia ser um silêncio que denunciava estádios de violência dentro dos relacionamentos humanos, talvez, já inculcados desde o próprio nascimento.

A conversa, por meio do convívio e de uma posição de escuta veraz, era a única saída para restabelecer a ordem inicial e primordial que permite a definição da intencionalidade. Nesse momento, não soube formular o problema, como de fato começo a fazer agora, mas decidi seguir a minha intuição. 


\section{Palavras em espanhol e intensificação semântica}

O caso das duas alunas, que apresentarei a seguir, parece exemplificar a problemática da intensificação semântica das palavras em espanhol, pois apenas quando decidimos fazer um passeio pelo seu bairro, juntas, a sua expressão abriu-se ao sentido, e a escrita foi liberada da crença mecânica de praticar frases e palavras, sendo incorporada ao fluxo da conversa. Uma delas tinha mostrado, durante as aulas, essa necessidade de copiar e repetir, inclusive em um momento dado, tinha tomado o espaço do professor, tentando reproduzir esse modelo de ensino ${ }^{19}$. Já nos momentos de convívio, ela tinha se mostrado receptiva, era fácil conversar com ela, pois deixava ver seu mundo pessoal e sua prática no ofício, no entanto, parecia não acreditar que os momentos de conversa pudessem estar sendo de aprendizado da língua estrangeira.

Depois do passeio pelo bairro, no qual visitamos a casa de uma delas, os lugares que costumavam frequentar e aqueles outros destinados ao apoio da comunidade, conseguiram escrever a partir da conversa, pois se tratava de um momento significativo, de compreensão do seu mundo junto a um tu, no qual se confia. Essa compreensão era de caráter linguístico e passava pelo uso da língua. $\mathrm{O}$ aprendizado da nova língua, nesse momento, reconduzia-se para o âmbito da intencionalidade, do que faz ou não sentido, segundo a própria experiência e segundo o convívio que movimentou o uso da língua.

No texto das alunas, apareceu, como fruto da conversa durante o passeio, uma impressão recorrente, a da falta de cuidado dos lugares (ou de atenção ou de participação) por parte das pessoas que neles habitam. Através dos espaços, elas conseguiram identificar atitudes humanas, que remetiam aos relacionamentos que compõem a comunidade.

Percebia-se nelas uma sensação de "não habitabilidade", de que os espaços em si não são nada, se não existe alguém que consiga habitá-los e esse habitar é um gesto que começa pela atenção ao relacionamento humano, às atitudes que nos permitem vincular-nos aos outros.

Nos seus textos, as palavras que apareciam em espanhol eram aquelas que tinham uma maior carga semântica. Pode-se dizer que os textos, pela proximidade do momento de passeio, ainda estavam tomados pela força vivencial de certas palavras que tinham surgido ao longo da conversa. Uma das alunas escreveu: " $\mathrm{Ha}$ blamos sobre mi barrio, que no há participación de las personas, pero que, so tiene interés, quando se tiene dinero. Pero yo participava de ongs como porejemplo na ilha do bispo, que me ajudou mucho al perder me vergonha". 
Esta mesma aluna desvelou outro aspecto da necessidade de habitar os espaços, durante o passeio, quando, ao chegar em um dos centros de trabalho social, observou que não existia nenhum lugar para poder estar tranquilo e em silêncio, segundo ela, "não parecia um lugar para as pessoas". Pareceu-me que, de algum modo, ela estava incorporando o silêncio com um valor ético, no sentido de ser um aspecto positivo e necessário na vida quotidiana da pessoa, podemos dizer que humanizado, com um significado de voltar sobre si próprio, de fazer manifestar a presença.

O mais interessante é que esta aluna conseguiu trasladar esse sentido da $h a$ bitabilidade dos espaços ao uso linguístico, pois, foi naquele momento quando ela conseguiu habitar novamente o uso da língua ${ }^{20}$ (ROCCA, 2010, p. 253), escrevendo a partir da sua intenção, do seu estado de ânimo. De algum modo, o passeio veio liberar a expressão do seu estado de ânimo, pois alguém estava presente, vendo e escutando com veracidade.

A conversa durante o passeio tinha ativado um assunto do interesse dela e isso permitiu que se ativasse, ao máximo, o princípio de relação nas duas línguas (espanhol e português), o que, no plano da experiência de uso, derivou em uma intensificação semântica, pois a escuta era indicador de um interesse pelo outro e a expressão estava vinculada aos aspectos anímicos da vida (atitudes, valores, estados de ânimo).

Conseguiu-se uma habitabilidade, no sentido linguístico, pois não foi um momento de "praticar", tentando se adequar a um método, e sim de "conversar", o que significava uma máxima abertura ao outro, através da escuta e da intensificação expressiva ${ }^{21}$. A língua estrangeira, novamente, funcionou como um recurso de ênfase de aqueles termos que guardavam um maior potencial expressivo e significativo. Esse poderia ser o ponto de partida para o desenvolvimento da sintaxe na nova língua, uma vez que já tínhamos identificado fontes de pensamento, que poderiam dar lugar à expressão da primeira pessoa dentro do âmbito comunitário.

Ao mesmo tempo, o caso se revela como uma possibilidade para refletir sobre a maneira como pode ser conduzida a escrita sem ter que quebrar o vínculo com a situação de fala, um aspecto que, tratando-se de alunos cujos mundos ade referências são principalmente orais, deve ser tido em consideração.

Existiria, numa primeira fase da escrita, fruto da continuidade da conversa entre um eu e um $t u$, no qual ainda não se atenderia às exigências lógico-formais próprias da escrita, em que a convenção não está completamente dominada, porque, ainda está sendo entendida. Porém, seria o substrato vivencial para o desenvolvimento da coerência interna, aquela que faz coincidir o que se pensa, com o que se diz e com as atitudes. 
Nesse nível, seria primordial a atenção por parte do professor no âmbito do léxico e do semântico, sentindo quais são as palavras e as expressões que funcionam, através de modos de intensificação (modulado da voz na entonação e sublinhado na escrita), como pilotagem de sentido no aprendizado da língua.

Os últimos casos apresentados mostram, por conseguinte, um significativo contraste entre a atitude que vem reforçar a adequação ao método, que, implica a instrumentalização da língua, tal e como o primeiro aluno demonstrou, ao me exigir que assumisse a figura do professor e "copiasse e traduzisse" palavras no quadro, e a mudança conflituosa e progressiva das últimas alunas, que pareciam entender o princípio de relação que opera no uso da língua, sendo elas as que se deparavam e intensificavam as próprias palavras na nova língua. As respectivas respostas revelavam atitudes divergentes, a primeira de supervivência social, que apenas pode ser garantida pela adequação aos modelos e ao método, e a segunda, de convívio comunitário, em que prevalece a dinâmica da relação no fluxo linguístico.

\section{Considerações finais}

Apesar de a oficina-escola ser um contexto formativo diferenciado, na sua filosofia e na sua atividade do contexto escolar e do contexto universitário, os casos apresentados neste estudo revelam semelhanças importantes no que diz respeito ao princípio de relação no uso e no aprendizado da língua. Dado o perfil dos alunos e sendo a oficina-escola um contexto onde prevalece a fala incorporada no trabalho e a observação dos fatos, o esperável seria que o aprendizado da língua pudesse ser realizado através do uso, ou seja, que o aprendiz admitisse, com uma atitude mais natural, o princípio de relação que favorece e sustenta o uso da língua, como força motriz do aprendizado.

Porém, pelo exposto no estudo de casos, os alunos da oficina-escola apresentavam, nas suas atitudes, um alto grau de assimilação ao modelo padrão que, embora, tivesse sido motivo de fracasso (ou pelo menos de "inadaptação"), parecia ser o único viável (e inevitável) para atingir certo status social ou, simplesmente, por ser reconhecível, por todos os que tinham sido escolarizados. Pelo que foi observado, os alunos que se mostraram mais sensíveis com o uso da língua foram aqueles que não estavam tão instrumentalizados nem tão intimidados pelo julgamento moral ou pela necessidade de se destacar entre o resto dos colegas, aqueles que entendiam o espaço da oficina-escola como um espaço formativo, para aprender um ofício engajado, de um modo espontâneo, no relacionamento humano.

Em questões linguísticas, existia, portanto, uma tendência a se assimilar o que conseguia dar um resultado homogêneo, em oposição paradoxal com o próprio con- 
texto formativo da oficina-escola, que tinha um caráter integrador, de incorporar os distintos perfis humanos (com suas habilidades naturais, personalidades, usos linguísticos, maneiras de estar no mundo), no ciclo formativo, através do fazer e do uso.

Foi significativa, também, a resposta daqueles alunos que mantinham uma relação distorcida e exagerada com a figura da autoridade, identificando o bom professor, que segue o modelo de ensino da língua, baseado na cópia e tradução, como um juiz da conduta. Isto revelava um problema primordial, pois se o referente do aprendiz manipulava o uso da língua como modo de propagar o medo e de estimular a coação, convertia o uso linguístico em lugar do engano e do estigma, inibindo o potencial formativo e educativo que este poderia oferecer.

Não obstante, durante a pesquisa, também alguns alunos apresentaram casos desviantes, afastados do modelo padrão, nos quais prevalecia uma abertura ao uso da nova língua através da escuta significativa e se revelava um mecanismo peculiar de intensificação semântica de certos termos na língua estrangeira, intensificando os movimento da intencionalidade.

Nesses casos, foi essencial a confiança, como estádio anímico, que se revela como um fio extremadamente frágil e também suscetível à manipulação, porém foi o que favoreceu a abertura ao uso comunitário e à própria intencionalidade, em contraste com as formas defensivas e adaptativas socialmente, que propiciava a adequação ao método.

\section{Language learning, use and principle of relation at the Workshop-School in João Pessoa}

Abstract

The case study presented in this paper focuses on the treatment of language use and principle of relation in language learning in the educational context of a Workshop-School, as opposed to the tendency to a strict application of a method, as usually happens in traditional classrooms. The cases described and reported in this paper reveal situations in which there are opposing forces (of integration and of exclusion) operating, which affect directly the educational possibilities of language use and the principle of relation in language learning. The study reveals, on one hand, that students to whom moral legitimization and reaching a determined social status are important tend to assimilate the standard educational model. On the other hand, we observed a tendency to use language, in which the meaningful listening and semantic intensification to create meaning predominated, as a way to conduct learning through communal relations.

Keywords: Language learning. Integration. Work. Community. 


\section{Notas}

1 Partiu-se da oposição (princípio de relação versus adequação ao método) formulada por Roca (2009) em "Relações de simulação e relações de autenticidade no ensino de Línguas vivas". Essa oposição surgiu ao longo da atividade de pesquisa-ação desenvolvida em contexto universitário e escolar, com o projeto intitulado "Para uma proposta de ensino E/LE dentro de um enfoque pragmático", que visava identificar as características do aprendizado pragmático no contexto do espanhol como língua estrangeira. Para uma compreensão mais completa do histórico do projeto, dos conceitos acunhados e da fundamentação teórica utilizada, sugere-se a leitura do capítulo indicado.

2 A este respeito, é importante lembrar que, no capítulo dedicado ao ensino de língua estrangeira (espanhol) dos Referenciais Curriculares para o ensino médio do Estado da Paraíba (DOURADO; ROCA, 2007), entendem-se as atitudes como um aspecto primordial para um aprendizado pragmático da língua. Embora, não possa ser tratado neste estudo, é importante ter em conta fatores como a capacidade natural para o aprendizado de segundas línguas, os componentes do entorno que favorecem esta capacidade e a própria motivação e necessidade por parte de quem aprende.

3 O projeto desenvolvido na Oficina-Escola de João Pessoa fez parte do mesmo projeto de pesquisa-ação, dessa vez, fora do âmbito da educação regulamentada pelo Estado, em um contexto de formação através do ofício. O projeto esteve coordenado pela professora Ma. del Pilar Roca (Proling/UFPB), sendo a autora deste artigo a professora encarregada da sua execução.

4 Uma aproximação às implicações linguísticas e pedagógicas do mencionado princípio encontra-se no artigo "O princípio do aprender fazendo no programa de oficinas-escola" (CAÑAS, 2013).

5 É importante destacar que a proposta das oficinas-escola não surge dentro das políticas educativas do Estado, pelo contrário, se apresenta como uma resposta crítica, desde o âmbito civil, ao fracasso que estava produzindo o modelo da sala de aula e ao desprestígio (ou insuficiência) que recai sobre a formação manual (e, nesse último aspecto, cumpre um papel fundamental o que a mentalidade cultural privilegia ou valoriza em cada momento). Posteriormente, se transformará em um programa nacional, porém será por intermédio do Ministério do Trabalho, pois o núcleo principal das oficinas-escola é a formação no/para o trabalho.

6 Segue-se Robert Stake (1989) no que diz respeito à caracterização do estudo de casos no âmbito da educação, pois o que nos interessa é o aprendizado da língua integrado no processo formativo, o que significa também atender às atitudes e aos valores que se revelam no tratamento das questões linguísticas.

7 Resultado dos primeiros estudos da pesquisa-ação foram os trabalhos de Roca (2007a; 2007b, 2006a), também de Cañas (2005; 2006; 2007; 2010), de Gómes (2005, 2007) e de Ribeiro (2006), todos eles citados no artigo indicado de Roca (2009). Nesses trabalhos, estava incorporada a prática qualitativa da análise de casos.

8 Esta característica da pesquisa qualitativa tem sido abordada no artigo "La lengua ordinaria y la enseñanza de E/LE” (MURGA; ROCA; CAÑAS, 2012), no qual é realizada uma primeira aproximação ao papel que pode cumprir o uso comum, nos processos de formação de professores de língua estrangeira (espanhol), em um contexto luso-falante.

9 Em Roca (2009) encontramos um bom exemplo da necessidade de avançar no uso da língua ordinária para a formação do professor e do pesquisador em contexto educativo. A autora se refere à compreensão do termo "convenção" durante os encontros e durante a conversa com as observadoras e a professora do projeto. Estas estavam entendendo o termo com um viés ideológico, no sentido de "modelos impostos externamente", quando, na verdade, a coordenadora entendia o termo no sentido de "formas negociadas", principalmente, referido à ortografia. Outro exemplo pode ser encontrado em Murga, Roca e Cañas (2012), quando tratada a compreensão que os professores em práticas tinham do termo "comunicativo" ou do "uso da língua", geralmente associado a "praticar", revelando, desse modo, uma crença fortemente instrumental do uso e do aprendizado da língua estrangeira. Nesse mesmo trabalho, apresenta-se um diagnóstico sobre a recorrência da expressão "correto/incorreto" (uma expressão transferida do seu português para o seu espanhol), que os professores em práticas mostravam, sobretudo, na hora de avaliar a atividade em sala de aula.

${ }^{10}$ Uma primeira aproximação ao valor formativo da conversa e sua distinção em respeito ao diálogo e à discussão, pode ser encontrada em Murga, Roca e Cañas (2012).

${ }^{11}$ As reações competitivas, por parte daqueles alunos que enfatizavam a adequação ao método e ao ideal formal, foram percebidas em outros momentos da pesquisa-ação (ROCA, 2009; CAÑ̃S, 2006, 2010). Coincidentemente, nesses casos, o relacionamento com a figura da autoridade dava-se em termos morais, do que é correto ou incorreto, projetando-se no aprendizado da língua ao enfatizar a prescrição gramatical e a tradução léxica.

${ }^{12} \mathrm{O}$ problema da substituição do uso por um implante, por uma apreciação de insuficiência que recai sobre o primeiro (sobretudo em sociedades que padecem uma forte diglossia, como é o caso do português do Brasil) foi tratado em Murga, Roca e Cañas (2012). 
${ }^{13}$ Entendemos língua morta como aquela que carece de uma comunidade natural de falantes. No aprendizado pressupõe a predominância de intermediários (o professor, o quadro, o livro) sobre o uso linguístico. A diferença entre língua viva e língua morta foi tratada ao longo da pesquisa-ação, em contexto formal (universidade e escola) e também na oficina-escola. Em Roca (2009) e Cañas (2011).

14 Para um estudo mais aprimorado da relação entre norma/uso no Brasil ver Faraco (2008) e para o problema da norma culta ver Bagno (2001). Para o problema da substituição do referente por um modelo no aprendizado da língua ver Roca (2012).

15 Entendo o eu-tu pela relação que se estabelece entre essas duas partes, tal e como se apresenta no pensamento de Martin Buber (2006).

16 Durante a pesquisa-ação, em contexto universitário e escolar, também se revelou o silêncio como um indicador importante no uso e do aprendizado da nova língua. Dependendo dos casos, o silêncio cobrava distintos matizes e sentidos. Ver Roca (2009) e Cañas (2010).

${ }^{17} \mathrm{Na}$ tese Lengua y conocimiento en Juan de Valdés (CAÑAS, 2012) é tratado o limite como um valor da experiência, segundo a análise do pensamento do autor. Ao longo da pesquisa-ação, foi um fator presente no tratamento do aprendizado da língua, pois a experiência do usuário sempre é finita e histórica. O aprendizado pelo uso pressupõe, necessariamente, uma maior consciência da noção de limite.

${ }^{18}$ Em Roca (2009) encontra-se uma distinção entre significado e sentido no aprendizado da língua estrangeira. Neste estudo, apresenta-se alguns traços particulares sobre o problema da intenção, originado na atividade com os alunos da oficina-escola.

${ }^{19}$ A tentativa de cobrir a posição do professor, quando este se afastava do centro da atividade, foi registrada e analisada em outros estudos de caso (ROCA, 2009; CAÑAS 2010).

${ }^{20}$ A ação de habitar o uso da língua surgiu em outros estádios da pesquisa-ação, a par da análise dos autores espirituais espanhóis do século XVI. Ver Roca (2010), onde se explica que "o estilo é a forma do sentido se é realizado em terra habitável", também Roca (2012) e a tese de Cañas (2011).

${ }^{21}$ Em Cañas (2010), descrevem-se dois casos semelhantes, nos quais a língua estrangeira funciona como um recurso de intensificação de um termo carregado de sentido para o aprendiz.

\section{Referências}

AMOR, Elias Manuel. Veinte años del programa de Escuelas Taller, Casas de Oficios y Talleres de empleo (Reflexiones para el futuro). Revista del Ministerio de Trabajo y Asuntos Sociales, Madrid, v. 71, p. 123-148, dic. 2008.

AGENCIA ESPAÑOLA DE COOPERACIÓN INTERNACIONAL. Programa de Patrimonio Cultural de la Cooperación Española. Escuelas Taller en Iberoamérica. Madrid: AECID, 2003.

BAGNO, Marcos. Norma linguística. São Paulo: Loyola, 2001.

BUBER, Martin. Yo y tú y otros ensayos. Buenos Aires: Lilmod, 2006.

CAÑAS, Rocío. Lengua y conocimiento en Juan de Valdés. 201 f. Tese (Doutorado em Linguística) - Universidade Federal da Paraíba, João Pessoa. p. 105-155. 2011.

Un estudio de casos sobre la clase de E/LE. Letr@Viv@, João Pessoa, v. 10, n.1, p. 204234, June, 2011.

. Corpo e fala na aprendizagem da LE. In: CONGRESSO INTERNACIONAL DA ASSOCIAÇÃO BRASILEIRA DE LINGUÍSTICA, 5, 2007, Belo Horizonte. Anais... Belo Horizonte: UFMG, 2007. p. 273-74.

. Repercussões do ideal formal no processo de aquisição da LE. In. JORNADA NACIONAL DE ESTUDOS LINGUÍSTICOS, XXI, 2006, João Pessoa. Anais... João Pessoa: Ideia, 2006. p. 2513-2518. 
O princípio do aprender fazendo no programa de oficinas-escola. Revista Eletrônica de Educação, São Carlos, v. 7, n. 3, p. 110-128, dez. 2013. Disponível em: <http://www.reveduc. ufscar.br>. Acesso em: 20 jan. 2014.

DOURADO, Maura Regina; ROCA, María del Pilar. Conhecimentos de Língua Estrangeira. In: Referenciais curriculares para o ensino médio da paraíba. João Pessoa: Governo do Estado da Paraíba, Secretaria de Estado de Educação e Cultura, Coordenadoria do Ensino Médio. 2006. p. 101-213.

ELLIOT, John. La investigación-acción en educación. Madrid: Morata, 1999.

FARACO, Carlos Alberto. Norma Culta Brasileira: desatando alguns nós. São Paulo: Parábola Editorial, 2008.

HUARTE DE SAN JUAN, Juan. Examen de Ingenios para las Ciencias. Madrid: Cátedra, 1989.

MOURA, Fernando (Org.). Oficina-Escola de João Pessoa. Dez anos reconstruindo o futuro. João Pessoa: Textoarte, 2011.

MURGA, María Hortensia; ROCA, María del Pilar; SERRANO, Rocío. La lengua ordinaria y la enseñanza de E/LE. Eutomia, Recife, v. 5, n. 2, p. 400-419, dez. 2011.

ROCA, María del Pilar. Modelo y referencia en la enseñanza y aprendizaje de E/LE. Abehache, v. 2 , n. 2 , p. $207-224,1^{\circ}$ sem. 2012.

Relações de simulação e relações de autenticidade no ensino de Línguas vivas. In: PEREIRA, Regina Celi; ROCA, Maria del Pilar (Org.). Linguística Aplicada, um caminho com diferentes acessos. São Paulo: Contexto, 2009. p. 143-171.

STAKE, Robert. Investigación con estudio de casos. Madrid: Morata, 1989.

VALDÉS, Juan. Diálogo de la lengua. Madrid: Cátedra, 1995. 